\title{
Evaluation of Quality of life, Social Support and Coping Strategies and Illness Adjustment in patients with breast cancer: Across sectional study
}

\author{
Hassan Okati-Aliabad \\ Zahedan University of Medical Sciences https://orcid.org/0000-0003-2058-8035 \\ Alireza Ansari-Moghadam \\ zahedan university of medical science \\ Mahdi Mohammadi \\ zahedan university of medical science \\ Fariba Shahraki-Sanavi \\ zahedan university of medical science \\ Shiva Kargar ( $\square$ shivakargar@yahoo.com ) \\ https://orcid.org/0000-0002-4570-6168
}

\section{Research}

Keywords: breast cancer, quality of life, social support, coping, adjustment

Posted Date: March 11th, 2021

DOI: https://doi.org/10.21203/rs.3.rs-242382/v1

License: (c) (i) This work is licensed under a Creative Commons Attribution 4.0 International License. Read Full License 


\section{Abstract}

Background: This study aimed to assess the quality of life (QOL), social support and coping strategies, and illness adjustment among breast cancer patients in general and on type of breast surgery.

Methods: We conducted a cross-sectional study at the Ali-Ebne-Abitaleb and Khatam-Al-Anbia hospitals in Zahedan, Iran, 2020. We recruited patients with breast cancer who underwent lumpectomy $(n=44)$, mastectomy $(n=64)$, and not any surgery $(n=15)$ by census method. Data collection tools were the breast cancer-specific module (QLQ-BR 23), The adjustment to illness measurement inventory for Iranian women with breast cancer (AIMI- IBC), and the multidimensional scale of perceived social support (MSPSS) questionnaires. We performed statistical analysis by ANOVA, independent sample t-test, Kruskal-Wallis, Mann-Whitney U-test, and multiple linear regression analysis to adjust for covariates.

Results: We recruited a total of 120 patients with breast cancer in this survey. $53.3 \%$ of patients underwent a mastectomy, $34.2 \%$ lumpectomy, and $12.5 \%$ of patients had not been surgery. Patients in the functioning scale reported high scores for body image (mean=78.61, SD=26.69) and future perspective (mean=55.27, SD=26.71). Patients on the symptom scale had a high score upset by hair loss (mean=49.16, SD=38.88). Generally, patients received a high social support level, especially from family members, and used a positive coping strategy to have high illness adjustment more than a negative coping strategy. Also, patients who underwent lumpectomy had a better sexual life and body image and more illness adjustment than the other two groups of patients.

Conclusion: Early detection of the disease, support for patients, and educational programs to use appropriate coping strategies can improve breast cancer women's quality of life and disease adaptation.

\section{Introduction}

Breast cancer is one of the most common female malignancy worldwide and the principal cause of death among women in developed and developing countries (1). Breast cancer is common among Iranian women, and although the incidence is lower than in Western countries, it has sharply risen in recent years and has become a threat to women (2).

Early detection and combination treatment such as chemotherapy, radiotherapy, hormone therapy, and surgical procedure can cure breast cancer (3). Surgical procedures, including mastectomy and breast-conserving therapy (lumpectomy), are the most prominent treatment for breast cancer (4). The survival is not different in these two surgical procedures (5), but patients who underwent lumpectomy had a better body image and quality of life (6). Also, a high QOL level could verily lead to long-term survival $(7,8)$. Evidence showed that the type of surgery does not affect any part of QOL except sexual function and body image domains $(9,10)$.

Some women with breast cancer reported physical and psychological distress due to cancer diagnosis and its treatment process that impair the different aspects of cancer patient life, such as family and social life $(11,12)$. Therefore, patients use various strategies for coping with these stressful conditions. A previous study in Iran has shown that coping strategies such as religious beliefs, accepting the reality of disease, and positive or negative thinking about the disease are essential strategies used by Iranian women with breast cancer, and spirituality as the most common coping strategies (13).

The perceived social support is an essential determinant of patients' capacity with breast cancer to cope with their disease and procedures. It could improve the QOL and ease the adjustment into life after treatment $(14,15)$. 
Previous studies have shown that Iranian cancer patients obtain high social support levels at all stages of disease $(16,17)$, and the most crucial source of this support are family members (18).

This study aimed to assess the influence of surgical type on QOL, coping strategies, illness adjustment, and social support in breast cancer patients in Zahedan, Southeastern Iran.

\section{Methods}

In this cross-sectional study, we selected 120 female breast cancer patients using the census method from the Clinical Oncology Department of Khatam-Al-Anbia hospital and the Radiotherapy Department Ali-Ebne-Abitaleb hospital in Zahedan, Southeastern Iran, 2020. The inclusion criteria included a confirmed breast cancer diagnosis, being18 years and older, and willingness to participate in this study. We used a self-administered questionnaire to collected socio-demographic information and clinical characteristics of patients. Also, we investigated the quality of life, social support, and adjustment to illness.

\section{Quality of Life (QLQ-BR23)}

The QLQ-BR23 consists of 23 questions of four functional scales (body image and sexual functioning, sexual enjoyment, future perspective) and four symptom scales (arm symptoms, breast symptoms, systematic therapy side effects, and being upset by hair loss). We calculated Item scores of the EORTC QLQ-BR23 according to the EORTC QLQ-C30 scoring manual (19). Each item had a five-point Likert score.

The range of scores for these questions is between 0 and 100. A high score for a functional domain represents a better functioning level, and a high score for a symptom domain represents a worse level of symptoms and more problems. This questionnaire is translated into Persian and validated in the previous study (20).

\section{Coping strategies and degree of adjustment (AIMI-IBC)}

We assessed women's coping strategies with breast cancer and the degree of adjustment with illness using an adjustment to illness measurement inventory for Iranian women with breast cancer (AIMI- IBC). This instrument had three domains (emotional turmoil, reasonable efforts, and avoidance) with 49 items. Each item had a five-point Likert score, ranging from 1 to 5 , and a higher score for each domain reflects frequent use of the coping manner. A cut-off for this scale is 122.5 . A mean score of $\geq 122.5$ indicates higher adjustment with the illness, and a mean score lower than 122.5 indicates not enough adjustment. The psychometric property of the AIMI- IBC questionnaire in Iranian women with breast cancer was confirmed (21).

\section{Multidimensional Scale of Perceived Social Support (MSPSS)}

Zimet and colleagues developed the MSPSS to measure perceived social support from friends, family, and significant others. This questionnaire consists of 12-items, and each item has a 5-point Likert type response format (from 1 = strongly disagree to $5=$ strongly agree). The score range is between 12 and 60, and higher scores reflect more perceived social support. The MSPSS had good validity and reliability in a previous study in Iran (22).

\section{Statistical analysis}

The collected data were analyzed using SPSS software, version 19.0. We used the chi-squared analysis to determine the frequency type of surgery across demographic characteristics of patients. We assessed the mean score of quality of life, social support, coping strategy, and illness adjustment among the surgical type variable using the 
ANOVA and Kruskal-Wallis tests. When one-way ANOVA and Kruskal-Wallis tests were significant, we made multiple comparisons with the least significant difference (LSD).

We performed multivariate linear regression to adjust for covariates to evaluate the surgical type's independent effects on QOL, coping strategy, illness adjustment, social support in the presence of potential confounders. A Pvalue $<0.05$ was considered significant.

\section{Results}

One hundred and twenty patients consented to participate in this study. The mean age of patients was 47.35 (SD10.67) years, and the time since diagnosis was 23.69 (SD20.38) months. Around half of the patients were of Sistani ethnicity (52.8\%), followed by Baluch (40.8\%) and others (6.7\%). Three-fourth of patients were married (75.8), and most were housewives (88.3\%). 16.3\% of patients had a family history of breast cancer. At the time of the survey, $40.8 \%$ of patients had been diagnosed with stage III breast cancer, followed by $34.2 \%$ stage IV, $22.5 \%$ stage II, $2.5 \%$ stage I. Most (90\%) of patients had received chemotherapy, and $64.2 \%$ received radiotherapy. More than half of the patients underwent mastectomy (53.3\%), followed by underwent lumpectomy (34.2\%), and $12.5 \%$ had not been surgery (table1).

Based on the results of Chi-square analysis, patients who underwent lumpectomy more had received radiotherapy than patients who underwent a mastectomy and not surgical $(\chi 2=6.22, p=0.04)$. Most patients who underwent mastectomy had stage III, stage VI of disease $(\chi 2=15.62, p=0.004)$.

\section{Quality of Life}

In the functioning scale, the higher mean scores were for body image $(78.61, S D=26.69)$ and future perspective (55.27, SD =26.81), respectively, while the lower mean scores were for sexual enjoyment $(14.86, S D=16.84)$ and sexual functioning $(14.16, S D=17.63)$. On the other hand, on the symptom scale, upset by hair loss $(49.16$, $\mathrm{SD}=38.88)$ and systematic therapy side effects $(45, \mathrm{SD}=17.42)$ scored the highest, followed by arm symptoms $(30.83, \mathrm{SD}=26.73)$ and breast symptoms $(13.63, \mathrm{SD}=18.58)$.

The significant difference across surgical groups was present in the functioning scales (body image, sexual functioning, and sexual enjoyment) and symptom scales (arm symptom). Patients who underwent lumpectomy had the best sexual function, sexual enjoyment, and body image. On the other hand, patients who underwent mastectomy had severe arm symptoms compared to patients who underwent a lumpectomy. After adjustment for the type of treatment (radiotherapy) and stage of the disease, this finding remained significant.

\section{Perceived Social Support (MPSS)}

The mean score of total social support was 45.71 (SD=9.92). Patients reported that they received the highest level of support from their family (mean=18.02, $S D=2.76$ ), followed by significant other (mean=14.45, SD=4.27) and friends (mean=13.23, SD =5.21). The statistical analysis showed that perceived social support's mean score and its domains had no significant difference among surgical groups $(p<0.05)$. The finding was uninfluenced even after controlling covariates (table2).

\section{Coping Strategies and IIIness Adjustment}


Patients who participated in this study used reasonable efforts coping strategy (mean $=4.07, S D=0.35$ ) more than avoidance (mean=3.39, SD=0.55) and emotional turmoil coping strategies (mean=2.93, SD=0.55). Also, patients presented a high degree of adjustment with their illness (mean=150.91, SD=16.29). Patients who underwent lumpectomy used more reasonable effort coping strategies $(p=0.009)$ and had a higher adjustment with illness $(p=0.01)$ than patients who underwent a mastectomy. These differences were still significant after adjustment for the covariate. The degree of illness adjustment in patients who underwent lumpectomy than those who underwent a mastectomy was not different (table2).

Table 1: Demographic characteristics of patients: in general and by Type of Surgery 


\begin{tabular}{|c|c|c|c|c|c|}
\hline \multirow[t]{2}{*}{ Variables } & \multirow{2}{*}{$\begin{array}{l}\text { Overall }(\mathrm{N}=120) \\
\mathrm{N}(\%)\end{array}$} & \multirow{2}{*}{$\begin{array}{l}\text { Lumpectomy }(\mathrm{N}=41) \\
\mathrm{N}(\%)\end{array}$} & \multirow{2}{*}{$\begin{array}{l}\text { Mastectomy(N=64) } \\
\mathrm{N}(\%)\end{array}$} & \multirow{2}{*}{$\begin{array}{l}\text { No } \\
\text { Surgical(N=15) } \\
N(\%)\end{array}$} & \multirow{2}{*}{$\begin{array}{l}\mathrm{P} \text { - } \\
\text { value }\end{array}$} \\
\hline & & & & & \\
\hline \multicolumn{6}{|l|}{ Age } \\
\hline mean $\pm S D$ & $47.35 \pm 10.67$ & $46.32 \pm 10.55$ & $48.08 \pm 10.51$ & $47.07 \pm 12.09$ & 0.71 \\
\hline$\leq 50$ & $75(62.5)$ & $28(68.3)$ & $37(57.8)$ & $10(66.7)$ & 0.52 \\
\hline$>50$ & 45 (37.5) & 13 (31.7) & 27 (42.2) & $5(33.3)$ & \\
\hline \multicolumn{6}{|l|}{$\begin{array}{l}\text { Time of since } \\
\text { diagnosis }\end{array}$} \\
\hline mean $\pm S D$ & $23.69 \pm 20.38$ & $19.15 \pm 17.61$ & $27.73 \pm 21.72$ & $18.87 \pm 18.99$ & 0.08 \\
\hline $6>$ & $22(18.3)$ & 8 (19.5) & $10(15.6)$ & $4(26.7)$ & 0.33 \\
\hline $6-12$ & $43(35.8)$ & $17(41.5)$ & $20(31.2)$ & $6(40)$ & \\
\hline $24-12$ & $17(14.2)$ & $8(19.5)$ & $8(12.5)$ & $1(6.7)$ & \\
\hline $24<$ & 38 (31.7) & $8(19.5)$ & $26(40.6)$ & $4(26.7)$ & \\
\hline \multicolumn{6}{|l|}{ Marital status } \\
\hline Married & $113(94.2)$ & $40(97.6)$ & $60(93.8)$ & $13(86.7)$ & 0.29 \\
\hline Un married & $7(5.8)$ & $1(2.4)$ & $4(6.2)$ & $2(13.3)$ & \\
\hline \multicolumn{6}{|l|}{ Educational level } \\
\hline $\begin{array}{l}\text { Primary or lower } \\
\text { School }\end{array}$ & 64 (53.3) & $17(41.5)$ & $39(60.9)$ & $8(53.3)$ & 0.16 \\
\hline $\begin{array}{l}\text { Secondary-High } \\
\text { School }\end{array}$ & $43(35.8)$ & $16(39)$ & $21(32.8)$ & $6(40)$ & \\
\hline College & $13(10.8)$ & $8(19.5)$ & $4(6.2)$ & $1(6.7)$ & \\
\hline \multicolumn{6}{|l|}{ Ethnicity } \\
\hline sistan & $63(52.5)$ & $23(56.1)$ & $33(51.6)$ & $7(46.7)$ & 0.71 \\
\hline baluch & $49(40.8)$ & $15(36.6)$ & $26(40.6)$ & $8(53.3)$ & \\
\hline other & $8(6.7)$ & $3(7.3)$ & $5(7.8)$ & $0(0)$ & \\
\hline \multicolumn{6}{|l|}{ Level of income } \\
\hline $\begin{array}{l}\text { Equal to } \\
\text { expenditures }\end{array}$ & 33.3))40 & $19(46.3)$ & $17(26.6)$ & $4(26.7)$ & 0.09 \\
\hline $\begin{array}{l}\text { Lower than } \\
\text { expenditures }\end{array}$ & $80(66.7)$ & $22(53.7)$ & $47(73.4)$ & $11(73.3)$ & \\
\hline \multicolumn{6}{|l|}{ Place of residence } \\
\hline urban & 93 (77.5) & $33(80.5)$ & $47(73.4)$ & $13(86.7)$ & 0.46 \\
\hline rural & $27(22.5)$ & 8 (19.5) & $17(26.6)$ & $2(13.3)$ & \\
\hline
\end{tabular}




\begin{tabular}{|c|c|c|c|c|c|}
\hline \multicolumn{6}{|l|}{ Employed status } \\
\hline housewife & $106(88.3)$ & $33(80.5)$ & $60(93.8)$ & $13(86.7)$ & 0.11 \\
\hline Employed & $14(11.7)$ & $8(19.5)$ & $4(6.2)$ & $2(13.3)$ & \\
\hline \multicolumn{6}{|c|}{ Menopausal status } \\
\hline Pre menopause & $73(60.8)$ & $15(36.6)$ & $26(40.6)$ & $6(40)$ & 0.91 \\
\hline Post menopause & 47 (39.2) & $26(63.4)$ & $38(59.4)$ & $9(60)$ & \\
\hline \multicolumn{6}{|l|}{ Stage of disease } \\
\hline Stage I, Stage II & $30(25)$ & $17(41.5)$ & $13(20.3)$ & $0(0)$ & 0.004 \\
\hline Stage III & $49(40.8)$ & $17(41.5)$ & $26(40.6)$ & $6(40)$ & \\
\hline Stage IV & $41(34.2)$ & $7(17.1)$ & $25(39.1)$ & $9(60)$ & \\
\hline \multicolumn{6}{|l|}{$\begin{array}{l}\text { Family history of } \\
\text { breast cancer }\end{array}$} \\
\hline yes & (16.3) 16 & $6(14.6)$ & $10(15.6)$ & $0(0)$ & 0.26 \\
\hline no & (86.7) 104 & $35(85.4)$ & $54(84.4)$ & $15(100)$ & \\
\hline \multicolumn{6}{|l|}{ Type of treatment } \\
\hline \multicolumn{6}{|l|}{ Chemotherapy } \\
\hline yes & $113(94.2)$ & $37(90.2)$ & $61(95.3)$ & $15(100)$ & 0.32 \\
\hline no & $7(5.8)$ & $4(9.8)$ & $3(4.7)$ & $0(0)$ & \\
\hline \multicolumn{6}{|l|}{ Radiotherapy } \\
\hline yes & $77(64.2)$ & $31(75.6)$ & $40(62.5)$ & $6(40)$ & 0.04 \\
\hline no & $43(35.8)$ & $10(24.4)$ & $24(37.5)$ & $9(60)$ & \\
\hline
\end{tabular}

Table 2: Average scores of Quality of Life, Perceived Social Support, Coping Strategies in the total patient and according to Type of Surgery 


\begin{tabular}{|c|c|c|c|c|c|c|}
\hline & $\begin{array}{l}\text { Overall } \\
(\mathrm{N}=120) \\
(\mathrm{M} \pm \mathrm{SD})\end{array}$ & $\begin{array}{l}\text { Lumpectomy }(\mathrm{N}=41) \\
(\mathrm{M} \pm \mathrm{SD})\end{array}$ & $\begin{array}{l}\text { Mastectomy }(\mathrm{N}=64) \\
(\mathrm{M} \pm \mathrm{SD})\end{array}$ & $\begin{array}{l}\text { No } \\
\text { Surgical( } N=15) \\
(M \pm S D)\end{array}$ & $\begin{array}{l}\mathrm{P} \text { - } \\
\text { value }\end{array}$ & $\begin{array}{l}\text { Adjusted } \\
\text { P-value } \\
\mathrm{h}\end{array}$ \\
\hline \multicolumn{7}{|l|}{$\begin{array}{l}\text { BR23 } \\
\text { functional } \\
\text { scales }^{c}\end{array}$} \\
\hline $\begin{array}{l}\text { Body } \\
\text { Image }\end{array}$ & $\begin{array}{l}78.61 \\
\pm 26.69\end{array}$ & $91.05 \pm 16.07$ & $67.44 \pm 28.97$ & $92.22 \pm 17.94$ & $0.001^{b}$ & 0.001 \\
\hline $\begin{array}{l}\text { Sexual } \\
\text { functioning }\end{array}$ & $\begin{array}{l}14.86 \\
\pm 16.84\end{array}$ & $20.32 \pm 17.28$ & $11.97 \pm 16.12$ & $12.22 \pm 16.01$ & $0.03^{b}$ & 0.006 \\
\hline $\begin{array}{l}\text { Sexual } \\
\text { enjoyment }\end{array}$ & $\begin{array}{l}14.16 \pm \\
17.63\end{array}$ & $19.51 \pm 18.22$ & $11.97 \pm 17.17$ & $8.88 \pm 15.25$ & $0.04^{b}$ & 0.04 \\
\hline $\begin{array}{l}\text { Future } \\
\text { perspective }\end{array}$ & $\begin{array}{l}55.27 \pm \\
26.71\end{array}$ & $60.97 \pm 25.71$ & $50.52 \pm 25.88$ & $60 \pm 31.37$ & $0.11^{b}$ & 0.16 \\
\hline \multicolumn{7}{|l|}{$\begin{array}{l}\text { BR23 } \\
\text { Symptom } \\
\text { Scales }{ }^{d}\end{array}$} \\
\hline $\begin{array}{l}\text { Systemic } \\
\text { therapy } \\
\text { side effects }\end{array}$ & $\begin{array}{l}45 \pm \\
17.42\end{array}$ & $47.85 \pm 15.64$ & $45.16 \pm 17.93$ & $36.50 \pm 18.23$ & $0.08^{\mathrm{b}}$ & 0.18 \\
\hline $\begin{array}{l}\text { Breast } \\
\text { symptoms }\end{array}$ & $\begin{array}{l}13.68 \pm \\
18.58\end{array}$ & $18.29 \pm 19.82$ & $11.45 \pm 18.15$ & $10.55 \pm 15.25$ & $0.05^{b}$ & 0.1 \\
\hline $\begin{array}{l}\text { Arm } \\
\text { symptoms }\end{array}$ & $\begin{array}{l}30.83 \pm \\
26.73\end{array}$ & $29.26 \pm 27.41$ & $35.24 \pm 26.89$ & $16.29 \pm 18.71$ & $0.03^{b}$ & 0.007 \\
\hline $\begin{array}{l}\text { Upset by } \\
\text { hair loss }\end{array}$ & $\begin{array}{l}49.16 \pm \\
38.88\end{array}$ & $47.15 \pm 36.49$ & $48.43 \pm 40.25$ & $57.77 \pm 40.75$ & $0.65^{b}$ & 0.31 \\
\hline \multicolumn{7}{|l|}{ MSPSS } \\
\hline Family & $\begin{array}{l}18.02 \pm \\
2.76\end{array}$ & $18.48 \pm 2.55$ & $17.90 \pm 2.22$ & $17.26 \pm 4.80$ & $0.15^{b}$ & 0.3 \\
\hline Friends & $\begin{array}{l}13.23 \pm \\
5.21\end{array}$ & $14.60 \pm 4.47$ & $12.31 \pm 5.31$ & $13.40 \pm 6.16$ & $0.13^{b}$ & 0.2 \\
\hline $\begin{array}{l}\text { significant } \\
\text { other }\end{array}$ & $\begin{array}{l}14.45 \pm \\
4.27\end{array}$ & $15.07 \pm 3.87$ & $13.93 \pm 4.41$ & $15 \pm 4.72$ & $0.31^{b}$ & 0.2 \\
\hline $\begin{array}{l}\text { Total score } \\
\text { of social } \\
\text { support }\end{array}$ & $\stackrel{ \pm}{9.9245 .71}$ & $48.17 \pm 8.53$ & $44.15 \pm 9.68$ & $45.66 \pm 13.31$ & $0.12^{\mathrm{a}}$ & 0.3 \\
\hline \multicolumn{7}{|l|}{$\begin{array}{l}\text { Coping } \\
\text { Strategies }\end{array}$} \\
\hline $\begin{array}{l}\text { Emotional } \\
\text { turmoil }\end{array}$ & $\begin{array}{l}2.93 \pm \\
0.55\end{array}$ & $2.82 \pm 0.52$ & $3.03 \pm 0.52$ & $2.83 \pm 0.72$ & $0.13^{\mathrm{a}}$ & 0.11 \\
\hline $\begin{array}{l}\text { Reasonable } \\
\text { efforts }\end{array}$ & $\begin{array}{l}4.07 \pm \\
0.35\end{array}$ & $4.19 \pm 0.34$ & $4 \pm 0.28$ & $4.02 \pm 0.53$ & $0.01^{\mathrm{a}}$ & 0.02 \\
\hline Avoidance & $\begin{array}{l}3.39 \pm \\
0.55\end{array}$ & $3.40 \pm 0.52$ & $3.40 \pm 0.53$ & $3.34 \pm 0.69$ & $0.92^{\mathrm{a}}$ & 0.8 \\
\hline
\end{tabular}


a P-value based on ANOVA tests. ${ }^{b}$ P-value based on Kruskal Wallis tests. ${ }^{c}$ For functional scales, higher scores indicate better functioning, ${ }^{\mathrm{d}}$ For symptom scales, higher scores indicate worse functioning, ${ }^{\mathrm{h}}$ p-value adjusted with radiotherapy and stage of the disease

\section{Discussion}

In this study, we investigated the areas of quality of life, social support, coping strategy, and illness adjustment in 120 patients with breast cancer in Zahedan, southeastern Iran, in general, and based on mastectomy and lumpectomy or no surgery. Patients had the best score in body image and future perspective and the worst in sexual enjoyment and sexual function. The symptom index's highest mean score was related to the side effects of treatment and the discomfort caused by hair loss, consistent with other studies (23-25). Studies have shown that cancer patients' different life quality areas are not static and change in various stages of the disease, after diagnosis, before and after treatment, and indifferent treatment methods that need special attention (26). Surgery to protect patients' breasts (lumpectomy) is performed in the early stages of cancer, improving body image, and improving life quality (6). In this study, patients who underwent lumpectomy or did not have any surgery had a better body image and fewer worries about the future than patients who underwent a mastectomy. Previous studies reported that patients who underwent lumpectomy had a better body image than those who experienced a mastectomy (27)(28).

On the other hand, in this study, lumpectomy patients showed better sexual performance and enjoyment than other patients. A survey in Taiwan showed that the type of surgery affected only functional scores of BR23-FS and that patients undergoing lumpectomy reported better BR23-FS scores than patients undergoing mastectomy (29). A German study also found that patients with conservative breast treatment (BCT) had a better quality of life on most BR-23 scales (30). Cancer patients use various strategies to deal with the health and psychosocial issues associated with a cancer diagnosis. Evidence showed that most Iranian women use active methods to deal with breast cancer, such as acceptance, religious coping, and planning (31), positively affecting these patients' psychological health and health behaviors, leading women more adaptable to their disease (32). In this study, patients mostly used positive coping strategies such as coping with the disease, avoiding negative thoughts about the condition, and a high illness adjustment rate. Also, lumpectomy patients tried harder to cope with their illness than mastectomy patients and eventually became more adjustable to their illness. A previous study showed no significant difference in the total score of coping skills between the two groups of lumpectomy and mastectomy and the patients in the mastectomy group used the significantly more denial (33). Patients in this study had high social support, which received the most support from family members, consistent with other studies' $(34,35)$. A previous study showed that cancer survivors receive high social support and family members are the most crucial support source (18). In this study, patients received less support from friends, while other studies reported family and friends as the main sources of support for breast cancer survivors $(35,36)$. In the current study, women in the lumpectomy group received more social support than women in the mastectomy and non-surgical groups, but this difference was not statistically significant. Received social support may play an essential role in the type of response to surgery. A previous study showed that women who decided to reconstruct after mastectomy, social support from family, and other important people could play a role in satisfaction with body image after breast surgery (37). 


\section{Conclusions}

Early detection of the disease, support for patients, and educational programs to use appropriate coping strategies can improve breast cancer women's quality of life and disease adaptation. Providing emotional and social support from patients' family members and treatment team, informing and educating patients to use positive coping strategies can reduce some of the psychological stress resulting from breast cancer diagnosis and treatment.

\section{Declarations}

\section{Acknowledgments}

The authors would like to thank all patients that participated in this study. We also appreciated all the health care workers in the Radiotherapy Department of Ali-Ebne-Abitaleb hospital and the clinical oncology department of Khatam-Al-Anbia hospital.

\section{Authors' contributions}

HOA, SK, and AAM participated in designing the study.

SK and FSS participated in data collection.

MM and SK participated in data analysis.

HOA and SK participated in preparing the manuscript.

All authors have read and approved the final version of the manuscript.

\section{Funding:}

This article is part of the corresponding author master's thesis, and Zahedan University of Medical Sciences has supported this work.

\section{Availability of data and materials}

The datasets used are available on reasonable request.

\section{Ethics approval and consent to participate}

The Ethics Committee of Zahedan University of Medical Sciences approved this study (IR.ZAUMS.REC.1399.010). The aim of the study was given to patients, and written informed consent was obtained from all participants.

\section{Consent for publication}

Not applicable.

\section{Competing interests}

The authors declare that there is no conflict of interest.

\section{Abbreviations}


$\mathrm{QOL}=$ quality of life

AIMI- IBC= The adjustment to illness measurement inventory for Iranian women with breast cancer

MSPSS= Multidimensional Scale of Perceived Social Support

$\mathrm{BCT}=$ conservative breast treatment

\section{References}

1. Shin HR, Boniol M, Joubert C, Hery C, Haukka J, Autier P, et al. Secular trends in breast cancer mortality in five East Asian populations: Hong Kong, Japan, Korea, Singapore and Taiwan. Cancer science. 2010;101(5):1241-6. https://doi.org/10.1093/jjco/hyx099

2. Ebrahimi E, Sellars E, Shirkoohi R, Harirchi I, Ghiasvand R, Mohebbi E, et al. The NCCN criterion "young age at onset" alone is not an indicator of hereditary breast cancer in iranian population. Cancer Prevention Research. 2019;12(11):763-70. https://doi.org/10.1158/1940-6207.capr-19-0056

3. De Aguiar SS, Bergmann A, Mattos IE. Quality of life as a predictor of overall survival after breast cancer treatment. Quality of Life Research. 2014;23(2):627-37. https://doi.org/10.1007/s11136-013-0476-8

4. Caffo O, Amichetti M, Ferro A, Lucenti A, Valduga F, Galligioni E. Pain and quality of life after surgery for breast cancer. Breast cancer research and treatment. 2003;80(1):39-48. https://doi.org/10.1023/a:1024435101619

5. Jatoi I, Proschan MA. Randomized trials of breast-conserving therapy versus mastectomy for primary breast cancer: a pooled analysis of updated results. American journal of clinical oncology. 2005;28(3):289-94. https://doi.org/10.1097/01.coc.0000156922.58631.d7

6. Ganesh S, Lye M-S, Lau FN. Quality of life among breast cancer patients In Malaysia. Asian Pacific Journal of Cancer Prevention. 2016;17(4):1677-84. https://doi.org/10.7314/apjcp.2016.17.4.1677 .

7. Mols F, Vingerhoets AJ, Coebergh JW, van de Poll-Franse LV. Quality of life among long-term breast cancer survivors: a systematic review. European journal of cancer. 2005;41(17):2613-9.

https://doi.org/10.1016/j.ejca.2005.05.017

8. Fang FM, Liu YT, Tang Y, Wang CJ, Ko SF. Quality of life as a survival predictor for patients with advanced head and neck carcinoma treated with radiotherapy. Cancer. 2004;100(2):425-32. https://doi.org/10.1002/cncr.20010

9. Kiebert G, De Haes J, Van de Velde C. The impact of breast-conserving treatment and mastectomy on the quality of life of early-stage breast cancer patients: a review. Journal of Clinical Oncology. 1991;9(6):1059-70. https://doi.org/10.1200/jco.1991.9.6.1059

10. Montazeri A. Health-related quality of life in breast cancer patients: a bibliographic review of the literature from 1974 to 2007. Journal of experimental \& clinical cancer research. 2008;27(1):32. https://doi.org/10.1186/17569966-27-32

11. Terol M, Lopez-Roig S, Rodriguez-Marin J. Differences in quality of life: longitudinal study with cancer patients receiving chemotherapy treatment. Anales de Psicologia. 2000;16:111-22.

12. Knobf MT, editor Psychosocial responses in breast cancer survivors. Seminars in oncology nursing; 2007 : Elsevier. https://doi.org/10.1016/j.soncn.2006.11.009

13. Taleghani F, Yekta ZP, Nasrabadi AN. Coping with breast cancer in newly diagnosed Iranian women. Journal of Advanced nursing. 2006;54(3):265-72. https://doi.org/10.1111/j.1365-2648.2006.03808_1.x 
14. Drageset S, Lindstrøm TC. Coping with a possible breast cancer diagnosis: demographic factors and social support. Journal of advanced nursing. 2005;51(3):217-26. https://doi.org/10.1111/j.1365-2648.2005.03495.x

15. Li C-C, Chen M-L, Chang T-C, Chou H-H, Chen M-Y. Social support buffers the effect of self-esteem on quality of life of early-stage cervical cancer survivors in Taiwan. European Journal of Oncology Nursing. 2015;19(5):48694. https://doi.org/10.1016/j.ejon.2015.02.008

16. Heydari S, Salahshourian-fard A, Rafii F, Hoseini F. Correlation of perceived social support from different supportive sources and the size of social network with quality of life in cancer patients. Iran Journal of Nursing. 2009;22(61):8-18.

17. Naseri N, Taleghani F. Social support in cancer patients referring to Sayed Al-Shohada Hospital. Iranian journal of nursing and midwifery research. 2012;17(4):279.

18. Faghani S, Rahmani A, Parizad N, Mohajjel-Aghdam A-R, Hassankhani H, Mohammadpoorasl A. Social support and its predictors among Iranian cancer survivors. Asian Pacific Journal of Cancer Prevention.

2014;15(22):9767-71. https://doi.org/10.7314/apjcp.2014.15.22.9767

19. Fayers P, Aaronson NK, Bjordal K, Sullivan M. EORTC QLQ-C30 scoring manual: European Organisation for Research and Treatment of Cancer; 1995.

20. Montazeri A, Harirchi I, Vahdani M, Khaleghi F, Jarvandi S, Ebrahimi M, et al. The EORTC breast cancer-specific quality of life questionnaire (EORTC QLQ-BR23): translation and validation study of the Iranian version. Quality of Life Research. 2000;9(2):177-84.

21. Hajian S, Mehrabi E, Simbar M, Houshyari M, Zayeri F, Hajian P. Designing and psychometric evaluation of adjustment to illness measurement inventory for Iranian women with breast cancer. Iranian journal of cancer prevention. 2016;9(4). https://doi.org/10.17795/ijcp-5461

22. Salimi A, JOUKAR B, NIKPOUR R. Internet and communication: Perceived social support and loneliness as antecedent variables. 2009.

23. Marashi T, Taherianfar Z, Rakhsha A. Survey of quality of life of patients with breast cancer among women at Shahid Beheshti University of Medical science and Health service 2017. Journal of Health in the Field. 2018;6(1).

24. Sibhat SG, Fenta TG, Sander B, Gebretekle GB. Health-related quality of life and its predictors among patients with breast cancer at Tikur Anbessa Specialized Hospital, Addis Ababa, Ethiopia. Health and quality of life outcomes. 2019;17(1):165. https://doi.org/10.1186/s12955-019-1239-1

25. Jafari N, Farajzadegan Z, Zamani A, Bahrami F, Emami H, Loghmani A. Spiritual well-being and quality of life in Iranian women with breast cancer undergoing radiation therapy. Supportive Care in Cancer. 2013;21(5):1219-25. https://doi.org/10.1007/s00520-012-1650-1

26. Gao J, Dizon DS. Preparing for survivorship: quality of life in breast cancer survivors. The Journal of Sexual Medicine. 2013;10:16-20. https://doi.org/10.1111/jsm.12029

27. Jassim GA, Whitford DL. Quality of life of Bahraini women with breast cancer: a cross sectional study. BMC cancer. 2013;13(1):212. https://doi.org/10.1186/1471-2407-13-212

28. Yurek D, Farrar W, Andersen BL. Breast cancer surgery: Comparing surgical groups and determining individual differences in postoperative sexuality and body change stress. Journal of consulting and clinical psychology. 2000;68(4):697. https://doi.org/10.1037/0022-006x.68.4.697

29. Tsai H-Y, Kuo RN-C, Chung K-p. Quality of life of breast cancer survivors following breast-conserving therapy versus mastectomy: a multicenter study in Taiwan. Japanese Journal of Clinical Oncology. 2017;47(10):909-18. https://doi.org/10.1093/jjco/hyx099

Page 12/13 
30. Arndt V, Stegmaier C, Ziegler H, Brenner H. Quality of life over 5 years in women with breast cancer after breastconserving therapy versus mastectomy: a population-based study. Journal of cancer research and clinical oncology. 2008;134(12):1311. https://doi.org/10.1007/s00432-008-0418-y

31. Khalili N, Farajzadegan Z, Mokarian F, Bahrami F. Coping strategies, quality of life and pain in women with breast cancer. Iranian journal of nursing and midwifery research. 2013;18(2):105.

32. Kim J, Han JY, Shaw B, McTavish F, Gustafson D. The roles of social support and coping strategies in predicting breast cancer patients' emotional well-being: testing mediation and moderation models. Journal of health psychology. 2010;15(4):543-52. https://doi.org/10.1177/1359105309355338

33. Gupta B, Yaduvanshi R, Trivedi J, Nischal A. A comparative study of body image and coping style in breast cancer patients. Delhi Psychiatry Journal. 2012;15(1):177-82.

34. Alizadeh S, Khanahmadi S, Vedadhir A, Barjasteh S. The relationship between resilience with self-compassion, social support and sense of belonging in women with breast cancer. Asian Pacific journal of cancer prevention: APJCP. 2018;19(9):2469.

35. Forsythe LP, Alfano CM, Kent EE, Weaver KE, Bellizzi K, Arora N, et al. Social support, self-efficacy for decisionmaking, and follow-up care use in long-term cancer survivors. Psycho-Oncology. 2014;23(7):788-96. https://doi.org/10.1002/pon.3480

36. Corey AL, Haase JE, Azzouz F, Monahan PO. Social support and symptom distress in adolescents/young adults with cancer. Journal of Pediatric Oncology Nursing. 2008;25(5):275-84.

https://doi.org/10.1177/1043454208321117

37. Spatuzzi R, Vespa A, Lorenzi P, Miccinesi G, Ricciuti M, Cifarelli W, et al. Evaluation of social support, quality of life, and body image in women with breast cancer. Breast Care. 2016;11(1):28-32.

https://doi.org/10.1159/000443493

\section{Supplementary Files}

This is a list of supplementary files associated with this preprint. Click to download.

- STROBEchecklistcrosssectional.doc 